\title{
Immunolocalization of DNMT1 and DNMT3a in Salivary Gland Neoplasms
}

\author{
Carolina Cavaliéri Gomes ${ }^{\mathrm{b}}$ Carla da Silveira e Oliveira ${ }^{\mathrm{b}}$ \\ Luiz Gustavo Garcia Santos Pimenta a Luiz De Marco ${ }^{c}$ Ricardo Santiago Gomez ${ }^{\text {b }}$

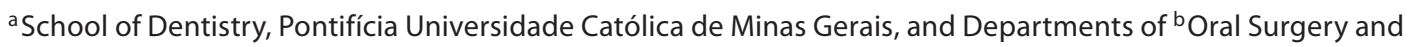 \\ Pathology and ' Pharmacology, Universidade Federal de Minas Gerais, Belo Horizonte, Brazil
}

\section{Key Words}

DNA methyltransferase - Methyltransferase - Salivary gland neoplasms $\cdot$ Methylation $\cdot$ Epigenetics

\begin{abstract}
Objective: Salivary gland neoplasms pathogenesis has not been well established. DNA methylation occurs when methyl groups are added to cytosine nucleotides in specific areas of the gene by the enzyme DNA methyltransferase (DNMT). This chemical modification can alter gene expression without altering DNA sequence. While DNMT3a is mostly involved in de novo methylation, DNMT1 acts as a maintenance methyltransferase. We aimed to investigate the immunoexpression of DNMT3a and DNMT1 in minor salivary gland neoplasms, comparing it with normal tissue. Material: Forty-four formalin-fixed and paraffin-embedded samples of pleomorphic adenoma, adenoid cystic carcinoma, mucoepidermoid carcinoma and polymorphous low-grade adenocarcinoma were included in the study. The DNMT1 and DNMT3a proteins were identified by using a highly sensitive polymer-based system. Results: Positive nuclear and cytoplasmic labeling for DNMT1 was observed in all samples, including the controls. Positive nuclear labeling for DNMT3a was found only in few neoplasms: 1 pleomorphic adenoma (9.0\%), 2 adenoid cystic carcinoma (16.6\%) and 1 mucoepidermoid (9.0\%) cases. Conclusion: Our results were not able
\end{abstract}

to demonstrate a clear correlation between DNMT1 and DNMT3a immunoexpression and salivary gland neoplasms development.

Copyright $\odot 2009$ S. Karger AG, Basel

\section{Introduction}

Salivary gland neoplasms are relatively uncommon lesions representing $0.3-1.5 \%$ of all biopsies processed in oral pathology laboratories, predominantly affecting major salivary glands [1]. Minor glands account for 9-23\% of all salivary gland neoplasms [1]. The intraoral site most commonly affected by benign and malignant neoplasms is the palate. Pleomorphic adenoma (PA) is the most common benign salivary gland neoplasm, while mucoepidermoid carcinoma (MEC) is the most common malignant one, followed by adenoid cystic carcinoma (ACC) and polymorphous low-grade adenocarcinoma (PLGA) [1].

Recent studies have demonstrated that the development and progression of human malignancies are associated with accumulation of alterations in proto-oncogenes and tumor suppressor genes [2,3]. Epigenetic alterations such as DNA methylation are important for human carcinogenesis, but its role in salivary gland neoplasias has not been well established.

\section{KARGER}

Fax +41613061234 E-Mail karger@karger.ch www.karger.com
Prof. Ricardo Santiago Gomez

Departamento de Patologia e Cirurgia, Faculdade de Odontologia

Universidade Federal de Minas Gerais, Av. Antonio Carlos 6627

Belo Horizonte, MG 31270-901 (Brazil)

Tel. +55 313409 2477, Fax +55 313409 2430, E-Mail rsgomez@ufmg.br 
Table 1. Clinical data of the cases of the normal salivary glands, PA, PLGA, adenoid cystic carcinoma and MEC included in the study

\begin{tabular}{|c|c|c|c|c|c|c|c|c|c|}
\hline & \multirow[t]{2}{*}{ Mean age, years } & \multicolumn{2}{|l|}{ Gender } & \multicolumn{6}{|l|}{ Location } \\
\hline & & female & male & lower lip & buccal mucosa & mandible & tongue & floor & palate \\
\hline NSG & $19(13-22)$ & 3 & 4 & 7 & - & - & - & - & - \\
\hline $\mathrm{PA}(\mathrm{n}=11)$ & $45(16-86)$ & 8 & 3 & - & 1 & - & 1 & 1 & 7 \\
\hline PLGA $(\mathrm{n}=10)$ & $54(20-84)$ & 5 & 4 & - & 1 & 1 & - & - & 6 \\
\hline $\operatorname{ACC}(n=12)$ & $38(21-85)$ & 10 & 2 & - & 3 & 2 & - & - & 7 \\
\hline $\operatorname{MEC}(n=11)$ & $45.5(14-73)$ & 7 & 3 & - & - & 5 & - & - & 5 \\
\hline
\end{tabular}

Figures in parentheses are ranges. NSG = Normal salivary glands.

DNA methylation is a phenomenon that occurs when methyl groups are added to cytosine nucleotides in specific areas of the gene by the enzyme DNA methyltransferase (DNMT) [4]. This chemical modification of DNA and its associated proteins can alter gene expression without altering DNA sequence. A number of DNMTs have been identified in mammals. DNMT3a and DNMT3b are mostly involved in de novo methylation, whereas DNMT1 acts as a maintenance methyltransferase [5-7]. Epigenetic silencing of gene expression by promoter $\mathrm{CpG}$ island hypermethylation has been shown to be important in the formation of a variety of cancers including oral squamous cell carcinoma [8]. Indeed, several studies have demonstrated hypermethylation events in ACC [9-11], MEC [11-13], PA [11-14], malignant PA [10], salivary duct carcinoma [11] and acinic cell carcinoma [11].

DNMTs were initially found to be overexpressed in tumorigenic cell lines [15] and in a few types of human neoplasms [16-18]. There is scarce information about DNMT1 immunoexpression in MEC, and apparently no data about immunoexpression pattern of DNMT3a in salivary gland neoplasms [12]. In this study, the immunoexpression pattern of DNMT3a and DNMT1 was investigated in benign and malignant minor salivary gland neoplasms, as well as in minor normal salivary glands.

\section{Materials and Methods}

Tissue Samples

Forty-four formalin-fixed and paraffin-embedded tissue samples of PA $(\mathrm{n}=11)$, ACC $(\mathrm{n}=12)$, MEC $(\mathrm{n}=11)$ and PLGA $(n=10)$ as well as the normal salivary glands $(n=7$; control tissue) included in the present study were obtained from the files of the Oral Pathology Service, School of Dentistry. The age, gender and tumor location in each group are summarized in table 1 . The nor- mal salivary gland tissues used as control were associated with oral mucocele biopsies. Tissue sections were stained with DNMT1 (diluted 1:150, clone 60B1220.1; IMGENEX, San Diego, Calif., USA) and DNMT3a antiserum (diluted 1:100, clone 64B1446; IMGENEX). Heat-induced epitope retrieval was performed with $10 \mathrm{mM}$ citrate buffer $\mathrm{pH} 6.0$ for $30 \mathrm{~min}$ in a steamer at $96^{\circ} \mathrm{C}$. Primary antiserum incubation was performed diluted in BSA $0.5 \%$ for $18 \mathrm{~h}$ at $4^{\circ} \mathrm{C}$. Immunohistochemical stains were performed using the high-sensitive polymer-based system (EnVision; Dako Corporation, Carpinteria, Calif., USA) with diaminobenzidine substrate solution as chromogen (Sigma, St. Louis, Mo., USA). The sections were counterstained with hematoxylin, dehydrated and mounted. A negative control, in which the primary antibody was omitted, was used in each reaction.

Only sections containing sufficient tumor cells to assess the antibody reactivity were included in our investigation. Two experienced pathologists examined multiple fields and made an independent analysis of each case, regardless of staining intensity. All samples were individually scored as grade 1 (less than $25 \%$ of positive cells) or grade 2 (more than $25 \%$ of positive cells). The score of the nuclear staining was performed separately from the cytoplasm.

\section{Results}

All lesions investigated showed broad positive nuclear and cytoplasmic labeling for DNMT1 (grade 2; fig. 1). In the normal salivary glands, positive nuclear staining for DNMT1 was observed in the ductal and acinar cells (grade 2). The immunoexpression pattern of DNMT3a in normal as well as in tumor cells is shown in figure 2. Ductal and acinar cells in normal salivary glands presented only cytoplasmic staining (grade 2 ). One PA $(9.0 \%)$ presented nuclear (grade 1) and cytoplasmic labeling (grade 2). Nuclear staining was also observed in 2 ACC (grade 2, 16.6\%) and 1 MEC (grade 1, 9.0\%; fig. 2). Therefore, only $4(9.0 \%)$ salivary gland neoplasms investigated presented DNMT3a nuclear staining. 
Fig. 1. DNMT1 immunohistochemical staining in a representative case of normal salivary gland (a), PA (b), ACC (c), MEC (d) and PLGA (e). All lesions (b-e) exhibited nuclear and cytoplasmic immunostaining in all cell layers, showing the same immunohistochemical staining pattern of normal salivary glands (a).


Fig. 2. DNMT3a immunohistochemical staining in a representative case of normal salivary gland (a), PA (b), ACC (c) and MEC (d). Ductal and acinar cells in normal salivary glands presented positive cytoplasmic labeling (a). Nuclear and cytoplasmic staining was observed in $1 \mathrm{PA}$ (b). Two ACC (c) and 1 case of MEC (d) showed positive nuclear labeling.

\section{Discussion}

In the present investigation we examined the immunoexpression pattern of two catalytically active DNMT in minor salivary gland neoplasms. Overexpression of both DNMT1 and DNMT3a has previously been reported in human neoplasias, including hepatocarcinomas, prostate and breast neoplasms, as well as gastric carcinomas [19-21]. Apparently, no such study has been performed in salivary gland neoplasms.
Hypermethylation of tumor suppressor genes that are normally unmethylated correlates with loss of expression in cancer cells. Hypermethylation of the tumor suppressor genes p16INK4a, p14ARF, p27Kip1, E-cadherin, 14-3$3 \sigma$, RASSF1A, DAPK, MGMT, RAR $\beta 2$ and RB1 has been demonstrated in some cases of salivary gland neoplasms $[9-14,22]$. Also, overexpression of various DNMTs in lung cancer may result in promoter hypermethylation of multiple tumor suppressor genes which then leads to poor prognosis [18]. 
While some studies revealed significant overexpression of DNMT1 in some human neoplasic tissues $[15,18$, 23-25], others have found no significant difference of this protein expression in neoplasms when compared to matched normal tissues $[26,27]$. Although DNMT1 is considered a maintenance form of DNMT that copies methylation patterns after DNA replication, in human cancers unknown factors could target this enzyme to unmethylated substrate DNA. So some authors believe that DNMT1 protein overexpression could result in de novo DNA hypermethylation during carcinogenesis [25]. Regarding DNMT3a, its expression was shown to be slightly increased in neoplasms from bladder, colon, kidney and pancreas when compared to matched normal tissue $[26,27]$, and it is suggested that its overexpression may take part in gastric carcinogenesis [28]. In hepatocarcinogenesis, a sequential decrease in cytoplasmic immunoreactivity for DNMT3a and a concurrent increase in nuclear DNMT3a were observed in high-grade dysplasia and carcinomas when compared to nonneoplastic and lowgrade dysplasia [29].
All cases included in our study showed a broad nuclear positive immunostaining for DNMT1 in all cell layers, and so did the fragments of normal salivary glands, suggesting that this enzyme may not be relevant to salivary gland tumorigenesis. In addition, only $9 \%$ of the salivary gland neoplasms analyzed presented nuclear expression of DNMT3a. Although hypermethylation of tumor suppressor genes is reported in salivary gland tumors [9-14, 22], our data suggests that these epigenetic changes might not be associated with an increased expression of DNMT3a.

In conclusion, our results were not able to demonstrate a clear correlation between DNMT1 and DNMT3a immunoexpression and salivary gland neoplasms development. The present findings, however, need to be confirmed by studies using other assays.

\section{Acknowledgements}

Grant sponsors: Milênio CNPq/MCT, PRONEX and FAPEMIG, Brazil. Dr. L. De Marco and R.S. Gomez are research fellows of CNPq.

\section{References}

1 Pires FR, Pringle GA, de Almeida OP, Chen SY: Intra-oral minor salivary gland neoplasms: a clinicopathological study of 546 cases. Oral Oncol 2007;43:463-470.

2 Perez-Ordoñez B, Beauchemin M, Jordan RC: Molecular biology of squamous cell carcinoma of the head and neck. J Clin Pathol 2006;59:445-453.

- 3 Tsantoulis PK, Kastrinakis NG, Tourvas AD, Laskaris G, Gorgoulis VG: Advances in the biology of oral cancer. Oral Oncol 2007;43: 523-534.

4 Shaw R: The epigenetics of oral cancer. Int J Oral Maxillofac Surg 2006;35:101-108.

5 Bestor TH, Ingram VM: Two DNA methyltransferases from murine erythroleukemia cells: purification, sequence specificity, and mode of interaction with DNA. Proc Natl Acad Sci USA 1983;80:5559-5563.

6 Okano M, Xie S, Li E: Cloning and characterization of a family of novel mammalian DNA (cytosine-5) methyltransferases. Nat Genet 1998;19:219-220.

7 Pradhan S, Bacolla A, Wells RD, Roberts RJ: Recombinant human DNA (cytosine-5) methyltransferase. I. Expression, purification, and comparison of de novo and maintenance methylation. J Biol Chem 1999;274: 33002-33010.

8 Ha PK, Califano JA: Promoter methylation and inactivation of tumour-suppressor genes in oral squamous-cell carcinoma. Lancet Oncol 2006;7:77-82.
-9 Uchida D, Begum NM, Almofti A, Kawamata H, Yoshida H, Sato M: Frequent downregulation of 14-3-3 sigma protein and hypermethylation of 14-3-3 sigma gene in salivary gland adenoid cystic carcinoma. Br J Cancer 2004;91:1131-1138.

10 Nishimine M, Nakamura M, Kishi M, et al: Alterations of p14ARF and p16INK4a genes in salivary gland carcinomas. Oncol Rep 2003;10:555-560.

11 Williams MD, Chakravarti N, Kies MS, et al Implications of methylation patterns of cancer genes in salivary gland neoplasms. Clin Cancer Res 2006;12:7353-7358.

$\checkmark 12$ Shieh YS, Shiah SG, Jeng HH, Lee HS, Wu CW, Chang LC: DNA methyltransferase 1 expression and promoter methylation of $\mathrm{E}$ cadherin in mucoepidermoid carcinoma. Cancer 2005; 104:1013-1021.

13 Guo XL, Sun SZ, Wang WX, Wei FC, Yu HB Ma BL: Alterations of pl6INK4a tumour suppressor gene in mucoepidermoid carcinoma of the salivary glands. Int J Oral Maxillofac Surg 2007;36:350-353.

14 Weber A, Wittekind C, Tannapfel A: Genetic and epigenetic alterations of $9 \mathrm{p} 21$ gene products in benign and malignant neoplasms of the head and neck. Pathol Res Pract 2003;199:391-397.
15 Kautiainen TL, Jones PA: DNA methyltransferase levels in tumourigenic and nontumourigenic cells in culture. J Biol Chem 1986;261:1594-1598.

-16 Sun L, Hui AM, Kanai Y, Sakamoto M, Hirohashi S: Increased DNA methyltransferase expression is associated with an early stage of human hepatocarcinogenesis. Jpn J Cancer Res 1997;88:1165-1170.

17 De Marzo AM, Marchi VL, Yang ES, Veeraswamy R, Lin X, Nelson WG: Abnormal regulation of DNA methyltransferase expression during colorectal carcinogenesis. Cancer Res 1999;59:3855-3860.

18 Lin RK, Hsu HS, Chang JW, Chen CY, Chen JT, Wang YC: Alteration of DNA methyltransferases contributes to $5^{\prime} \mathrm{CpG}$ methylation and poor prognosis in lung cancer. Lung Cancer 2007;55:205-213.

19 Girault I, Tozlu S, Lidereau R, Bièche I: Expression analysis of DNA methyltransferases $1,3 \mathrm{~A}$, and $3 \mathrm{~B}$ in sporadic breast carcinomas. Clin Cancer Res 2003;9:4415-4422.

-20 Saito Y, Kanai Y, Nakagawa T, et al: Increased protein expression of DNA methyltransferase (DNMT) 1 is significantly correlated with the malignant potential and poor prognosis of human hepatocellular carcinomas. Int J Cancer 2003; 105:527-532.

21 Patra SK, Patra A, Zhao H, Dahiya R: DNA methyltransferase and demethylase in human prostate cancer. Mol Carcinog 2002;33: 163-171. 
-22 Kishi M, Nakamura M, Nishimine M, Ikuta M, Kirita T, Konishi N: Genetic and epigenetic alteration profiles for multiple genes in salivary gland carcinomas. Oral Oncol 2005; 41:161-169.

-23 Issa JP, Vertino PM, Wu J, et al: Increased cytosine DNA-methyltransferase activity during colon cancer progression. J Natl Cancer Inst 1993;85:1235-1240.

24 Etoh T, Kanai Y, Ushijima S, et al: Increased DNA methyltransferase 1 (DNMT1) protein expression correlates significantly with poorer tumour differentiation and frequent DNA hypermethylation of multiple CpG islands in gastric cancers. Am J Patho 2004; 164:689-699.
25 Peng DF, Kanai Y, Sawada M, et al: Increased DNA methyltransferase 1 (DNMT1) protein expression in precancerous conditions and ductal carcinomas of the pancreas. Cancer Sci 2005;96:403-408.

26 Lee PJ, Washer LL, Law DJ, Boland CR, Horon IL, Feinberg AP: Limited up-regulation of DNA methyltransferase in human colon cancer reflecting increased cell proliferation. Proc Natl Acad Sci USA 1996;93:1036610370.
$>27$ Robertson KD, Uzvolgyi E, Liang G, et al: The human DNA methyltransferases (DNMTs) 1, 3a and 3b: coordinate mRNA expression in normal tissues and overexpression in neoplasms. Nucleic Acids Res 1999;27:2291-2298.

28 Ding WJ, Fang JY, Chen XY, Peng YS: The expression and clinical significance of DNA methyltransferase proteins in human gastric cancer. Dig Dis Sci 2008;53:2083-2089.

29 Choi MS, Shim YH, Hwa JY, et al: Expression of DNA methyltransferases in multistep hepatocarcinogenesis. Hum Pathol 2003;34: 11-17. 